\title{
PRESCRIPTION AUDIT USING THE WORLD HEALTH ORGANIZATION PRESCRIBING INDICATORS FOR INDOOR PATIENTS TREATED UNDER CMAAY/PMJAY INSURANCE SCHEMES IN A TERTIARY CARE TEACHING HOSPITAL
}

\author{
DEVENDER SACHDEV ${ }^{1 *}$, KARTIK JANARDAN SALWE ${ }^{2}$, ANOOP DEV $^{3}$, BINITA SINGHA $^{4}$, HAGE AMBING $^{5}$ \\ ${ }^{1}$ Department of Pharmacology, Tomo Riba institute of health and medical sciences, Naharlagun, Arunachal Pradesh, India. ${ }^{2}$ Department \\ of Pharmacology, Mahatma Gandhi Medical College and Research Institute, Sri Balaji Vidyapeeth, Puducherry, India. ${ }^{3}$ Department of \\ Community Medicine, Tomo Riba Institute of Health and Medical Sciences, Naharlagun, Arunachal Pradesh, India. ${ }^{4}$ Department of \\ Pharmacology, Tomo Riba Institute of Health and Medical Sciences, Naharlagun, Arunachal Pradesh, ${ }^{5}$ Deprtment of Medicine, Tomo Riba \\ insititute of Health and Medical sciences, Naharlagun, Arunachal Pradesh,India India. Email: drdevendersachdev@gmail.com
}

Received: 10 December 2021, Revised and Accepted: 12 January 2022

ABSTRACT

Objective: This study focused on the prescriptions audit of indoor patients treated under Pradhan Mantri Jan Arogya Yojana (PMJAY) and Chief Minister Arogya Arunachal Yojana (CMAAY) insurance schemes as per the World Health Organization (WHO) prescribing indicators.

Materials and Methods: Retrospective cross-sectional study was conducted and the prescriptions of around 960 patients were analyzed who were treated from June 2020 to December 2020 under CMAAY/PMJAY insurance schemes at Tomo Riba institute of Health and Medical Sciences in Arunachal Pradesh. Study was conducted in five departments and Information was collected through the review of case sheets. The post-operative day prescription was analyzed for the patients who have undergone surgery and the patients who were managed conservatively; admission day prescription was analyzed using the WHO core drug prescribing indicators. Following data were analyzed. (1) Average no of drugs prescribed per encounter; (2) percentage of encounter having antibiotic; (3) percentage of drugs prescribed by generic name; (4) percentage of encounters with an injection; and (5) percentage of drugs prescribed from the essential drug list.

Results: A total of 960 indoor patients treated under five departments, out of which 359 (37.4\%) treated under general surgery, 383 (39.9\%) under Obstetrics and Gynecology department, 65 (6.8\%) under ENT department, 68 (7.1\%) under orthopedics department, and 85 (8.9\%) under General medicine department. All departments taken together, the average number of drugs used per patient was 4.91 . Antibiotics were prescribed in $92.18 \%$ of the total patients when all departments were included, single antibiotic was used in $72.18 \%$, two antibiotics in $17.29 \%$, and three in $2.7 \%$ of the total patients. Overall, the generic names were written in $67.3 \%$ of the total drugs and the most commonly used route was parenteral route, in about $98.19 \%$ of the total prescribed drugs. From the essential drugs list, $89.33 \%$ of the total drugs were prescribed. Fixed drug combination was used in $13.59 \%$ of the total drugs prescribed.

Conclusion: In our study, the percentage of prescriptions with average no of drugs per prescription, antibiotic used, injections used were much higher when compared to the WHO core prescribing indicators. The reason might be because we have analyzed the prescription of indoor patients and most of them were post-operative patients, so it is justified. While prescribing, the physicians and surgeons followed WHO essential drug list but use of generic names was in few prescriptions. The generic name use to be more emphasized, encouraged, and promoted.

Keywords: Antibiotics, Essential drug list, Fixed drug combination, Generic name, Insurance Scheme, Routes, World Health Organization prescribing indicators.

(c) 2022 The Authors. Published by Innovare Academic Sciences Pvt Ltd. This is an open access article under the CC BY license (http://creativecommons.org/ licenses/by/4.0/) DOI: http://dx.doi.org/10.22159/ajpcr.2022v15i2.43819. Journal homepage: https://innovareacademics.in/journals/index.php/ajpcr

\section{INTRODUCTION}

Prescription audit helps to improve the quality of prescribing drugs in the institute. By prescription audit the quality of the prescribing drugs can be evaluated. It is a quality improvement process where a positive change can be made in the patients care. The standard of prescription reflects rational prescribing and the competence of the clinician $[1,2]$. The outcome and patient care can be improved by doing regular prescription audits and comparing it with set standards of prescription writing [3].

By doing regular prescription audits, the rational use of medicines can be motivated. As a result, the quality of prescription can be increased in a cost-effective way, decreasing the incidence of adverse drug reactions, and also increasing proper utilization of resources $[4,5]$.

The World Health Organization (WHO) has given the Internationally accepted criteria for standard prescription writing as a guide for good prescription [6-8]. The way of writing of prescriptions can be compared with the WHO given internationally accepted criteria $[4,9]$.
Various studies concerned with prescription audit have been done in the past [10-12].

Pradhan Mantri Jan Arogya Yojana (PMJAY) and Chief Minister Arogya Arunachal Yojana (CMAAY) are the initiatives of central and state Government, respectively, which are employed by the Chief Minister Arogya Arunachal Society for free cashless health-care services to the people of the State [13].

The present study was planned to analyze prescription audit using the WHO prescribing indicators for indoor patients treated under CMAAY/PMJAY insurance schemes at Tomo Riba institute of Health and Medical Sciences (TRIHMS) in Arunachal Pradesh, North East India with following objectives.

1. To investigate the rational use of drugs for completeness legibility and to characterize the drug use in the medical college as per the WHO recommended core drug use indicators and to analyze the prescription errors

2. To carry out a complete therapeutic audit and to know what was 
prescribed with what intention and with what benefit or what ill effects and at what cost to the community.

\section{METHODS}

This retrospective cross-sectional study (Prescription audit) was carried out in TRIHMS, Naharlagun, Arunachal Pradesh. The case records of all the indoor patients treated under department of General Surgery, Obstetrics and Gynecology. ENT, orthopedics and General Medicine from June 2020 to December 2020 under CMAAY/PMJAY insurance schemes were collected from the medical record Department of TRIHMS. A total of 960 patients treated under five departments, out of which 359 got treatment under surgery, 383 under Obstetrics and Gynae, 65 under ENT, 85 under medicine and 68 under orthopedics. The prescriptions written on the day of the admission for all cases who were managed conservatively and for all those patients who underwent surgery procedure, the prescriptions written post operatively (only the prescription followed immediately after surgery, not the subsequent prescriptions) were analyzed. The i.v fluids given were not taken in consideration.

The broad classification of the various cases according to the diagnosis was done and thereafter the prescriptions were analyzed using the WHO core drug prescribing indicators. For the diagnosis, which could not be grouped together and as it was long list to mention each, they were clubbed together in others category. The following things were analyzed.

1. Average no of drugs prescribed per encounter. The prescription with combination of drug was considered as one

2. The percentage of encounter in which the antibiotic was prescribed. Furthermore, the total no of antibiotic in every prescription was calculated

3. Percentage of drugs prescribed by generic name

4. Percentage of encounters with an injection

5. Percentage of drugs prescribed from the essential drug list.

\section{Statistical analysis}

Data were expressed as mean \pm SD, numbers and percentages. Collected data were entered into Microsoft_Excel_2019 and subsequently statistical analysis was done using the same.

\section{Ethics committee permission}

Ethical permission to conduct the hospital-based study was obtained from Institution Ethical Committee before commencement of the study (IHECTRIHMS/ETHICS/01/2019-20). Data confidentiality was maintained during and after data collection.

\section{RESULTS}

There were a total 960 indoor patients treated under PMJAY and CMAAY insurance schemes. Most patients (about 75\%) were treated under general surgery 359 (37.4\%) and Obstetrics and Gynecology department 383 (39.9\%). Patients treated under ENT, ortho and General Medicine were $65(6.8 \%), 68$ (7.1\%), and $85(8.9 \%)$, respectively. Female patients $(70 \%)$ were more benefitted than male patients $(29.9 \%)$ under these schemes than the male patients (Table 1 )

Average number of days stayed was maximum under department of Medicine ( 9.4 days), followed by orthopedics (8.7 days), General surgery (6.5 days), ENT (3.78 days), and least was under obstetrics and gynecology (3.73 days) (Table 2).

Out of 359 indoor patients treated under the department of General Surgery, maximum no of surgeries done was cholecystectomy (25.63\%), followed by appendix surgeries (13.65\%), excision (10.86\%), hernia/ hydrocele $(10 \%)$, and hemorrhoidectomy $(7.70 \%)$ related surgeries (Table 3).

Out of 383 indoor patients treated under department of obstetrics and gynecology, maximum no of surgeries done was lower segment cesarean section (LSCS) (69.9\%), followed by total abdominal hysterectomy (9.3\%), lap Cystectomy (6.2\%), myomectomy (3.3\%), Diagnostic laparoscopy for infertility (2.87\%), and surgeries for ectopic pregnancy (2.8\%) (Table 4).

Out of 65 indoor patients treated under department of ENT, maximum surgeries done were Tonsillectomy/adenotonsillectomy (53.8\%), followed by tympanoplasty $(10.7 \%)$, functional endoscopic sinus surgery $(9.2 \%)$, surgeries for fracture nasal bone $(9.2 \%)$, and tympanomastoidectomy (3\%) (Table 5).

Out of 68 patients treated under orthopedics, maximum surgeries done were open reduction and internal fixation (54.4), followed by spine surgeries (5.8\%) and implant removal (4.4\%) (Table 6).

Out of 85 patients managed under department of general medicine, nearly one forth were suffering from respiratory illness $(24.7 \%)$, followed by cerebrovascular accident (11.7\%), liver diseases (11.7\%), febrile illness (9.4\%), cardiac related problems (9.4\%), tuberculosis (8.2\%), carcinoma (5.8\%), and acute gastroenteritis and SLE (4.7\%) (Table 7).

Maximum no of average drugs used per case was by the department of obstetrics and gynecology (6.44), followed by the department of Medicine (4.31), ENT (3.96), Surgery (3.91), and Orthopedics (3.28). For all departments taken together ( 960 patients), the average no of drugs used per patient was 4.91 (Table 8).

Maximum prescriptions having antibiotics were prescribed by the Department of Obstetrics and Gynecology (100\%), followed by the Department of Orthopedics (97\%), Department of General Surgery (96.9\%), Department of ENT (89.2\%), and General Medicine (35.2\%). In most of the patients', single antibiotic was used. Including all the benefitted indoor patients' antibiotics was prescribed in $92.18 \%$, single antibiotic in $72.1 \%$, two antibiotics in $17.2 \%$, and three in $2.7 \%$ (Table 9).

Overall, the generic names were written in $67.3 \%$ of the total drugs prescribed. Maximum drugs written by generic names were prescribed by ENT department (85.2\%), followed by Obstetrics and Gynecology (74.9\%), General Medicine (74.3\%), General Surgery (52.7\%), and Orthopedics (43.9\%) Department (Table 10).

Overall, nearly $98 \%$ of the total drugs were given by parenteral route. Maximum drugs given by parenteral route were prescribed by Obstetrics and Gynecology Department (99.8\%), followed by Orthopedics (98.2\%), ENT (94.9\%), General Surgery (94.3\%), and

Table 1: Department wise number of benefitted indoor patients under CMAAY/PMJAY Insurance scheme

\begin{tabular}{llll}
\hline Departments & No of pts (\%) & Male (\%) & Female (\%) \\
\hline Gen surgery & $359(37.4)$ & $166(46.2)$ & $193(53.8)$ \\
OBGY & $383(39.9)$ & - & $383(100)$ \\
ENT & $65(6.8)$ & $33(50.7)$ & $32(49.3)$ \\
Ortho & $68(7.1)$ & $44(64.7)$ & $24(35.3)$ \\
Gen Medicine & $85(8.9)$ & $44(51.7)$ & $41(48.3)$ \\
Total & $960(100)$ & $287(29.9)$ & $673(70)$ \\
\hline
\end{tabular}

PMJAY: Pradhan Mantri Jan Arogya Yojana, CMAAY: Chief Minister Arogya Arunachal Yojana 
General Medicine (85.24\%) Department. Inhalational route was used maximum times by the general medicine department whereas syrups were used only few times (Table 11).

When all departments taken together, $89.33 \%$ of the drugs were essential drugs. Maximum essential drugs were written by orthopedics department (96.0\%) followed by ENT (95.7\%), General Medicine (93.7\%), General Surgery (92.2\%), and Gynecology (85.8\%) (Table 12).

Overall, $13.59 \%$ of drugs were with fixed drug combination. Maximum percentage of prescription with fixed dose combination were written by ENT department (18.67\%), followed by general surgery (14.82\%), obstetrics and gynecology (13.90\%), orthopedics (7.17\%), and general medicine (7.10\%).

Table 2: Department wise average stay of benefitted patients under CMAAY/PMJAY Insurance scheme

\begin{tabular}{ll}
\hline Departments & Days stayed (Days) \\
\hline Gen surgery & $6.5 \pm 6.36$ \\
Obstetrics and gynecology & $3.73 \pm 2.58$ \\
ENT & $3.78 \pm 3.30$ \\
Ortho & $8.7 \pm 5.54$ \\
Gen medicine & $9.4 \pm 7.23$ \\
\hline
\end{tabular}

PMJAY: Pradhan Mantri Jan Arogya Yojana, CMAAY: Chief Minister Arogya Arunachal Yojana
Most of the combinations used were combination of antibiotics with beta lactamase inhibitors, either clavulanic acid, sulbactam or tazobactam except cefixime with dicloxacillin which was used in 14 patients and imipenem and cilastatin combination in two patients (Table 13)

\section{DISCUSSION}

PMJAY and CMAAY are the initiatives of central and state Govt., respectively, which is being implemented by the Chief Minister Arogya Arunachal Society with a vision to accord quality and cashless healthcare services to the people of the State envisaging Universal health care to all by 2030 [13].

Prescription audit helps to improve the quality of the prescription. Standards of prescriptions can be improved by doing it on regular basis. This study was planned to analyze the prescriptions for the indoor patients who were benefitted under CMAAY/PMJAY insurance scheme for better understanding of prescription pattern which can help in better implementation of scheme.

As per our study conducted in 960 patients $70 \%$ were female and $30 \%$ were male, this was because from the Department of Obstetrics and Gynecology around 383 patients were included. Average days of patient stay in hospital were in between 3.73 days and 9.4 days. In most of the admitted cases, surgery was done except in a few cases which were managed conservatively. The maximum number of cases dealt by

Table 3: Broad classification of various diagnosis and surgeries done on indoor patients treated under department of General Surgery

\begin{tabular}{|c|c|c|c|}
\hline $\begin{array}{l}\text { Broad classification of Surgeries } \\
\text { done by Gen Surgery }\end{array}$ & Surgeries & No. of patients & Percentage \\
\hline Lap cholecystectomy & $\begin{array}{l}\text { Laparoscopic cholecystectomy -90, Laparoscopic } \\
\text { cholecystectomy plus appendicectomy -2 }\end{array}$ & 92 & 25.6 \\
\hline Appendix related & $\begin{array}{l}\text { Appendicectomy } 43 \text {, conservative } \mathrm{m} / \mathrm{m} \text { appendicitis/ } \\
\text { appendicular abscess }-4 \text {, appendicular abscess drainage- } 2\end{array}$ & 49 & 13.6 \\
\hline Various excision surgeries & -- & 39 & 10.8 \\
\hline Hernia/Hydrocele & $\begin{array}{l}\text { Hernial repair/Hernioplasty/Herniotomy-31, } \\
\text { Hydrocele-4, hydrocele plus herniotomy- } 1\end{array}$ & 36 & 10 \\
\hline Hemorrhoidectomy plus others & Haemorrhoidectomy-24, Fistulectomy-3, Fissurectomy-1 & 28 & 7.7 \\
\hline Exploratory laparotomy & 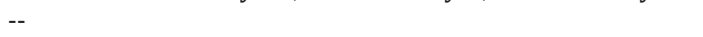 & 19 & 5.2 \\
\hline Incision and drainage & I and D/Liver abscess drainage/Psoas abscess drainage & 18 & 5 \\
\hline Thyroid surgeries & $\begin{array}{l}\text { Hemithyroidectomy } 12 \text {, Total Thyroidectomy }-1 \text {, Thyroid } \\
\text { lobectomy-1 }\end{array}$ & 14 & 3.8 \\
\hline Gastric surgeries & Gastrectomy-6, Subtotal Gastrectomy -5 & 11 & 3 \\
\hline Ca Breast related surgeries & Ca Breast (MRM-3, Breast Ca conservative $\mathrm{m} / \mathrm{m}-1$ ) & 4 & 1.1 \\
\hline Diabetic foot surgeries & -- & 3 & 0.8 \\
\hline Orchidopexy & Orchidopexy & 3 & 0.8 \\
\hline Others & Others & 43 & 11.9 \\
\hline Total & & 359 & 100 \\
\hline
\end{tabular}

Table 4: Broad classification of various surgeries done on indoor patients treated under department of obstetrics and gynecology

\begin{tabular}{lll}
\hline Broad classification of surgeries done by OBGY & No. of patients & Percentage \\
\hline LSCS & 268 & 69.9 \\
TAH & 36 & 9.3 \\
Lap cystectomy & 24 & 6.2 \\
Myomectomy & 13 & 3.3 \\
DL for infertility & 11 & 2.87 \\
Surgeries for ectopic pregnancy & 11 & 2.8 \\
Surgeries for UV prolapse & 5 & 1.3 \\
Laparotomy (Ruptured uterus plus cystectomy, Atonic & 5 & 1.3 \\
PPH, Adhesiolysis, ovariotomy) & 2 & 0.5 \\
VH & 2 & 0.5 \\
DL for tubal blockage & 1 & 0.2 \\
Wertheim radical hysterectomy & 5 & 1.3 \\
Others (bilateral salpingo oophorectomy, conservative & & \\
m/m for wound gaping for TAH, NVD, Tubal & & 100 \\
recanalization, wide resection of right vulva & 383 & \\
Total & & \\
\hline LSCS: Lower segment Cesarean section, TAH: Total Abdominal Hysterectomy, DL: Diagnostic laparoscopy, VH: Vaginal Hysterectomy, NVD: Normal vaginal delivery
\end{tabular}


Table 5: Broad classification of various surgeries done on indoor patients treated under department of ENT

\begin{tabular}{lll}
\hline $\begin{array}{l}\text { Broad classification of surgeries } \\
\text { done by ENT }\end{array}$ & $\begin{array}{l}\text { No. of } \\
\text { patients }\end{array}$ & Percentage \\
\hline Tonsillectomy/Adenotonsillectomy & 35 & 53.8 \\
Tympanoplasty & 7 & 10.7 \\
FESS & 6 & 9.2 \\
Fracture nasal bone & 6 & 9.2 \\
Tympanomastoidectomy & 2 & 3 \\
Tracheostomy & 1 & 1.5 \\
Others & 8 & 12.3 \\
Total & 65 & 100 \\
\hline
\end{tabular}

FESS: Functional endoscopic sinus surgery

Table 6: Broad classification of various surgeries done on indoor patients treated under department of orthopedics

\begin{tabular}{lll}
\hline $\begin{array}{l}\text { Broad classification of surgeries } \\
\text { done by orthopedic department }\end{array}$ & No. of patients & Percentage \\
\hline ORIF & 37 & 54.4 \\
Spine surgeries & 4 & 5.8 \\
Implant removal & 3 & 4.4 \\
Others & 24 & 35.2 \\
Total & 68 & 100 \\
\hline
\end{tabular}

ORIF: Open reduction internal fixation

Table 7: Broad classification of illnesses of indoor patients treated under department of general medicine

\begin{tabular}{lll}
\hline $\begin{array}{l}\text { Broad classification of patients } \\
\text { treated by General Medicine }\end{array}$ & No. of patients & Percentage \\
\hline Respiratory illness & 21 & 24.7 \\
CVA & 10 & 11.7 \\
Hepatitis/CLD & 10 & 11.7 \\
Febrile illness & 8 & 9.4 \\
Cardiac related & 8 & 9.4 \\
Tuberculosis & 7 & 8.2 \\
Carcinoma & 5 & 5.8 \\
Acute gastroenteritis & 4 & 4.7 \\
SLE & 4 & 4.7 \\
Others & 8 & 9.4 \\
Total & 85 & 100 \\
\hline
\end{tabular}

CVA: Cerebrovascular accident, CLD: Chronic liver disease, SLE: Systemic Lupus erythematosus

Table 8: Average number of drugs used per case on indoor patients treated under department of general surgery, obstetrics and gynecology, ENT, orthopedics, and general medicine

\begin{tabular}{ll}
\hline Departments & Average no of drugs per case \\
\hline General surgery & 3.91 \\
Obstetrics and gynecology & 6.44 \\
ENT & 3.96 \\
Orthopedics & 3.28 \\
General Medicine & 4.31 \\
\hline
\end{tabular}

General Surgery department was cholecystectomy, LSCS by Obstetrics and Gynecology Department, Tonsillectomy/Adenotonsillectomy by ENT Department, Open reduction internal fixation by orthopedics department and respiratory illnesses by General Medicine Department. This part of ours study comprising of the broad classification of the various surgeries/illness is also part of our other publication.

In this study, the average no of drugs used per patient was 4.91 which is much more than WHO core prescribing indicator which suggests the optimum value for average number of drugs per prescription should be less $2 \%$. This may be because the prescriptions which we have considered were mainly of post-operative patients except medicine cases and those managed conservatively and for post-operative patient there is need to prescribe antibiotics, analgesic, antiulcer, and other drugs.

Our study results were different from study conducted by Shah et al., in which there was more number of drugs prescribed per patient (7.31) than our study while by Chandelkar et al., it was much lesser number (1.84 per patient) than our study; however, our study results were similar to the studies conducted by Afroz et al. and Mishra et al., where the average no of drugs of drugs per prescription was 4.22 and 4.004 , respectively [14-17]. The reason for this variation might be because the studies were conducted in different type of patients and situations.

As per our study, antibiotics were prescribed in $92.18 \%$ of total cases, which is much higher than recommendation of the WHO core prescribing indicator where optimal value is $<30 \%$. In some other studies, the percentage of encounter with antibiotics was $54 \%$ and $21.78 \%[18,19]$. The reason could be similar, that is, our study was conducted in mainly postoperative and critically ill patients where antibiotics are prescribed commonly.

The generic names were used in $67.3 \%$ of the total drugs prescribed by all departments is less than the WHO core prescribing indicator which suggests that $100 \%$ of the drugs prescribed should be with generic names. In some of the other studies conducted by Rai et al., Sunny et al., and Chakraborthy et al., the percentage of generic names were $11.3 \%$, $3.6 \%$, and $47 \%$, respectively, which is less than our study results [20-22].

In our study, the most common route for giving medicine was parenteral route $(98.19 \%)$ which is much higher than the WHO core prescribing indicator which indicates the optimum value of percentage of encounter with injections should be less than $20 \%$. As per the study conducted by Rai et al., $42.3 \%$ of drugs were injectable and another study by Sharonjeet et al., $75.17 \%$ of drugs were injectable which is less than the result of our study (98.19\%) [20,23]. This may be due to the post-operative and critically ill patients' prescriptions were analyzed where parenteral therapy is commonly used.

In this study, $89.33 \%$ of the total drugs prescribed by all departments were from the essential drugs list which is comparable to the WHO recommendation that all medicines (100\%) should be from the essential drug list. In some other studies, conducted by Singh et al., Sema et al., Chandra et al. and Singh et al., percentage of drugs from the essential drug list was $81 \%, 100 \%, 72.91 \%$, and $88.3 \%$, respectively, which is less than the result of our study except that conducted by Chandra et al. [24-27]. In our institute, we have framed our own essential drug list based on the WHO essential list and the physicians and surgeons are sensitized at regular interval to follow it. This may be the reason behind as most of the drugs are prescribed from it.

The percentage of total drugs prescribed as fixed dose combination was $13.59 \%$. All the fixed dose combinations were combinations of antibiotics with beta lactamase inhibitors like clavulanic acid, sulbactam, and tazobactam. Apart from this, in 14 patients, combination of cefixime with dicloxacillin (both antibiotics) and in two patients, imipenem and cilastatin was used. These combinations are commonly used in therapy to increase the spectrum of activity, decrease resistance and inhibit the degradation of antibiotics. There was no irrational fixed dose combination used.

The study was done for limited period of time and the admitted patients in various departments were unequal. Furthermore, study was done specially in admitted patients under specified insurance schemes, so we found it difficult to correlate the data in our study with the few available studies. More studies are needed to extrapolate our results for a larger population. 
Table 9: Percentage of prescriptions having antibiotics written for indoor patients treated under department of General Surgery, Obstetrics and Gynecology, ENT, orthopedics, and General Medicine

\begin{tabular}{llllll}
\hline Department & Total no of patients & One antibiotic (\%) & Two antibiotics (\%) & Three antibiotics (\%) & Total (\%) \\
\hline General Surgery & 359 & $248(69.08)$ & $98(27.29)$ & $2(0.55)$ & $348(96.93)$ \\
OBGY & 383 & $313(81.72)$ & $48(12.53)$ & $22(57.44)$ & $383(100)$ \\
Orthopedics & 68 & $54(79.41)$ & $12(17.64)$ & - & $66(97.05)$ \\
General Medicine & 85 & $20(23.52)$ & $8(9.4)$ & $2(2.35)$ & $30(35.29)$ \\
ENT & 65 & $58(89.23)$ & - & - & $58(89.23)$ \\
Total & 960 & $693(72.18)$ & $166(17.29)$ & $26(2.70)$ & $885(92.18)$ \\
\hline
\end{tabular}

Table 10: Percentage of drugs written with generic names for indoor patients treated under department of general surgery, obstetrics and gynecology, ENT, orthopedics, and general medicine

\begin{tabular}{llll}
\hline Departments & $\begin{array}{l}\text { Total number } \\
\text { of patients }\end{array}$ & $\begin{array}{l}\text { Total number of } \\
\text { drugs prescribed }\end{array}$ & $\begin{array}{l}\text { Number of drugs with } \\
\text { Generic names (\%) }\end{array}$ \\
\hline General Surgery & 359 & 1403 & $739(52.7)$ \\
OBGY & 383 & 2466 & $1847(74.9)$ \\
General Medicine & 85 & 366 & $272(74.3)$ \\
Orthopedics & 68 & 223 & $98(43.9)$ \\
ENT & 65 & 257 & $219(85.2)$ \\
Total & 960 & 4715 & $3175(67.3)$ \\
\hline
\end{tabular}

Table 11: Percentage of drugs given by parenteral and other routes for indoor patients treated under department of general surgery, obstetrics and gynecology. ENT, orthopedics, and general medicine

\begin{tabular}{|c|c|c|c|c|c|c|c|c|}
\hline \multirow[t]{2}{*}{ Departments } & \multirow{2}{*}{$\begin{array}{l}\text { Total no of drugs } \\
\text { prescribed }\end{array}$} & \multicolumn{6}{|c|}{ Routes used for drug administration (\%) } & \multirow[t]{2}{*}{ Syrups $(\%)$} \\
\hline & & i. v. & i. $\mathbf{m}$. & s.c. & (i. v. + i. m+s.c) & Oral & Inhalational & \\
\hline General Surgery & 1403 & 1135 (80.9) & $186(13.3)$ & $2(0.14)$ & 1323 (94.29) & $76(5.41)$ & $4(0.29)$ & $3(0.21)$ \\
\hline OBGY & 2466 & $1588(64.4)$ & $870(35.3)$ & - & $2458(99.7)$ & $8(0.32)$ & - & - \\
\hline General Medicine & 366 & $271(74.0)$ & 37 (10.1) & $4(1.09)$ & $312(85.24)$ & $17(4.64)$ & 43 (11.7) & $3(0.8)$ \\
\hline Orthopedics & 223 & $157(70.4)$ & $62(27.8)$ & - & 219 (98.2) & $4(1.8)$ & - & - \\
\hline ENT & 257 & $206(80.1)$ & $38(14.8)$ & - & $244(94.9)$ & $13(5.0)$ & - & - \\
\hline Total & 4715 & 3431 (72.7) & $1193(25.30)$ & $6(0.12)$ & 4630 (98.19) & $118(2.05)$ & $47(0.99)$ & $6(0.12)$ \\
\hline
\end{tabular}

Table 12: Percentage of drugs having essential drugs for indoor patients treated under department of general surgery, obstetrics and gynecology. ENT, orthopedics, and general medicine

\begin{tabular}{llll}
\hline Departments & Total no of patients & Total no of drugs prescribed & Essential drugs (\%) \\
\hline General surgery & 359 & 1403 & $1293(92.2)$ \\
Obstetrics and gynecology & 383 & 2466 & $2116(85.8)$ \\
General medicine & 85 & 366 & $343(93.7)$ \\
Orthopedics & 68 & 223 & $214(96.0)$ \\
ENT & 65 & 257 & $246(95.7)$ \\
Total & 960 & 4715 & $4212(89.33)$ \\
\hline
\end{tabular}

Table 13: Percentage of prescription with fixed dose combination for indoor patients treated under department of general surgery, obstetrics and gynecology, ENT, orthopedics, and general medicine

\begin{tabular}{llll}
\hline Departments & Total no of patients & Total no of drugs prescribed & $\begin{array}{l}\text { Total number of drugs with fixed dose } \\
\text { combination (\%) }\end{array}$ \\
\hline General surgery & 359 & 1403 & $208(14.82)$ \\
OBGY & 383 & 2466 & $343(13.90)$ \\
General medicine & 85 & 366 & $26(7.10)$ \\
Orthopedics & 68 & 223 & $16(7.17)$ \\
ENT & 65 & 257 & $48(18.67)$ \\
Total & 960 & 4715 & $641(13.59)$ \\
\hline
\end{tabular}

\section{CONCLUSION}

There were no irrational combinations used. Most of the drugs used were from the essential drug list. The percentage of prescriptions with average no of drugs per prescription used was higher when compared to the WHO core prescribing indicators. Considering the aspect that our data is mainly of the post-operative and critically ill indoor patients, there was need for antibiotic and analgesic to be used, hence it is justified. While prescribing the physicians and surgeons followed the WHO essential drug list as they are sensitized at regular interval to follow it. Generic names were in few prescriptions. It needs to be more emphasized, encouraged and promoted. Overall, our study shows that in the insurance scheme of CMAAY/PMJAY running in our institute, 
there was rational use of drugs. However, there is need for more studies in this region to extrapolate our results in larger population.

\section{Data availability}

The primary data gathered by the authors, which supports the finding of this study are available from the corresponding author and can be shared if a request is being received after due permission from the Chief Medical Superintendent, TRIHMS, Govt. of Arunachal Pradesh and the Chief Executive officer, CMAAY.

\section{ACKNOWLEDGMENTS}

We acknowledge all the respective clinical departments, Chief Medical Superintendent (TRIHMS), Chief Executive officer (CMAAY) for permitting us to conduct the research and we also express our gratitude to the medical record section (TRIHMS), Insurance desk (TRIHMS) for the valuable help to conduct this study.

\section{AUTHORS CONTRIBUTIONS}

The conception or design of the work and data collection was done by Devender Sachdev. The data analysis and interpretation were done by Kartik Salwe. The drafting of the article was done by Anoop Dev and Binita Singha and critical revision of the article by Hage Ambing

\section{CONFLICTS OF INTEREST}

The authors declare that there are no conflicts of interest and no relationship with the industry.

\section{FUNDING SOURCES}

There was no special funding for this research. All the patients included were from PMJAY and CMAAY insurance schemes.

\section{REFERENCES}

1. World Health Organization. Rational Use of Medicines by Prescribers and Patients. Geneva: World Health Organization; 2005. Available from: https://apps.who.int/iris/bitstream/handle/10665/20236/B115_40-en. pdf? sequence $=1$ \&isAllowed $=\mathrm{y}$ [Last accessed on 2021 Nov 09

2. Abidi A, Gupta S, Kansal S. Prescription auditing and drug utilization pattern in a tertiary care teaching hospital of Western UP. Int J Basic Clin Pharmacol 2012;1:184-90.

3. Seden K, Kirkham JJ, Kennedy T, Lloyd M, James S, McManus A, et al. Cross-sectional study of prescribing errors in patients admitted to nine hospitals across North West England. BMJ Open 2013 3:e002036.

4. Solanki ND, Shah C. Prescription audit in outpatient department of multispecialty hospital in western India: An observational study. Int J Clin Trials 2015;2:14-9.

5. Hussain S, Parveen Z, Gupta S, Kumar D, Gupta R, Thakur S. A study of prescription auditing in rural health care setting of north India. Int J Med Sci Public Health 2016;5:2461-65.

6. Ahsan M, Shaifali I, Mallick AK, Singh HO, Verma S, Shekhar A. Prescription auditing based on World Health Organization (WHO) prescribing indicators in a teaching hospital in North India. Int J Med Res Rev 2016;4:1847-52.

7. Bekele N, Tadesse J. Prescription auditing based on World Health Organization (WHO) prescribing indicators: A case of Dilla University referral hospital. J Drug Delivery Ther 2018;8:21-5.

8. Karki N, Prasad P, Joshi RR, Shrestha BK. Drug utilization pattern by using WHO core prescribing indicators in orthopedics and obstetrics/ gynecology departments of a tertiary care hospital. J Lumbini Med Coll 2019;7:6.

9. Scrivener R, Morrell C, Stevenson K, Bromwich N. Principles for Best Practice in Clinical Audit. Abingdon: National Institute for Clinical Excellence, Radcliffe Medical Press; 2002.

10. BegumT, Khan MI, Kawser S, Huq ME, Majid N, Akhter A. An audit of rational use of antibiotics in a tertiary hospital. Delta Med Col J 2014;2:64-7

11. Tunger O, Dinc G, Ozbakkloglu B, Atman UC, Algun U. Evaluation of rational antibiotic use. Int J Antimicrob Agents 2000;15:131-5.

12. Karna K, Sharma S, Inamdar S, Bhandari A. Study and evaluation of medication errors in a tertiary care teaching hospital a baseline study. Int J Pharm Sci 2012;4:587-93.

13. Chief Minister Arogya Arunachal Yojana. Ayushman Bharat. Available from: https://www.cmaay.com/CMAAY_home.aspx [Last accessed on 2021 Nov 05].

14. Shah RB, Gajjar BM, Desai SV. Drug utilization pattern among geriatric patients assessed with the anatomical therapeutic chemical classification/defined daily dose system in a rural tertiary care teaching hospital. Int J Nutr Pharmacol Neurol Dis 2012;2:258-65.

15. Chandelkar UK, Rataboli PV. A study of drug prescribing pattern using WHO prescribing indicators in the state of Goa, India. Int J Basic Clin Pharmacol 2014;3:1057-61.

16. Abidi A, Gupta S, Kansal S, Ramgopal. Prescription auditing and drug utilization pattern in a tertiary care teaching hospital of western UP. Int J Basic Clin Pharmacol 2012;1:184-90.

17. Mishra S, Sharma P. Prescription audit and drug utilization pattern in a tertiary care teaching hospital in Bhopal. Int J Basic Clin Pharmacol 2016;5:1845-9.

18. Pallavi PS, Tejasree B, Krishnakanth PV. Study of prescription patterns of antibiotic in tertiary care hospital. Int J Biomed Res 2016;7:372-4.

19. Cheekavolu C, Pathapati RM, Laxmansingh KB, Saginela SK, Makineedi VP, Siddalingappa, Kumar A. Evaluation of drug utilization patterns during initial treatment in the emergency room: A retroprospective pharmacoepidemiological study. ISRN Pharmacol 2011;2011:261585.

20. Rai S, Bhuvana K, Sowmya C, Sahana HV, Yaseen M. Prescription audit at a tertiary care teaching hospital. Natl J Physiol Pharm Pharmacol 2018;8:1271-4.

21. Sunny D, Roy K, Benny SS, Mathew DC, Naik GJ, Gauthaman K. Prescription audit in an outpatient pharmacy of a tertiary care teaching hospital-a prospective study. J Young Pharm 2019;11:417-20.

22. Chakraborthy A, Riyash M, Srinivasan K, Lakshmi V. Prescription audit towards quality indicators at a tertiary care teaching hospital in South India. J Patient Saf Qual Improv 2020;8:99-105.

23. Kaur S, Rajagopalan S, Kaur N, Shafiq N, Bhalla A, Pandhi P, Malhotra S. Drug utilization study in medical emergency unit of a tertiary care hospital in North India. Emerg Med Int 2014;2014:973578.

24. Singh IP, Singh R, Shanker V, Aujla SS. Prescription audit and assessment of drug use pattern using World Health Organization prescribing indicators in a tertiary care teaching and referral hospital in Himachal Pradesh, India. J Med Sci Clin Res 2018;6:377-84.

25. Sema FD, Asres ED, Wubeshet BD. Evaluation of rational use of medicine using WHO/INRUD core drug use indicators at Teda and Azezo Health Centers, Gondar Town, Northwest Ethiopia. Integr Pharm Res Pract 2021;10:51-63

26. Chandra S, Khan IN, Mateenudin M, Chandrakapure A, Maaz S, Mubin F. Drug utilization study in OPD of a tertiary care hospital in a rural area of Jalna, Maharashtra, India by using WHO prescribing indicators. Int J Basic Clin Pharmacol 2018;7:55-8.

27. Singh T, Banerjee B, Garg S, Sharma S. A prescription audit using the World Health Organization recommended core drug use indicators in a rural hospital of Delhi. J Educ Health Promot 2019;8:37. 